\title{
Educação estatística em um ambiente de modelagem matemática nas aulas do ensino médio
}

\author{
Luzinete de Oliveira Mendonça* \\ Celi Espasandin Lopes** \\ Elizabeth Soares***
}

\begin{abstract}
Resumo
Este trabalho decorre de uma pesquisa de mestrado realizada em 2008, quando buscamos observar o desenvolvimento dos alunos em um ambiente de modelagem matemática na implementação da Educação Estatística no Ensino Médio. Tomamos como objeto de análise o desenvolvimento dos alunos de duas turmas de $3^{\circ}$ ano de uma escola estadual na Grande São Paulo. É um estudo de natureza qualitativa, com foco na compreensão da construção do conhecimento estatístico dos alunos, e a análise de dados se dá a partir das categorias emergentes dos dados coletados no desenvolvimento do projeto, considerando os objetivos previstos em cada etapa. Os resultados observados dão indícios de que o ambiente investigativo é propício para motivar os alunos a participarem de forma ativa na construção dos conceitos inerentes à educação estatística.

Palavras-chave: Ambiente de modelagem matemática, Educação Estatística, Ensino Médio.
\end{abstract}

\section{Statistical education in an environment of mathematics modeling in high school}

\begin{abstract}
This paper derives from a research conducted in 2008, when we seek to observe the development of students in an environment of mathematical modeling in the implementation of Education Statistics in High School. We take as the object of analysis the development of students from two classes of third year of a state school in São Paulo. It is a qualitative study with focus on understanding the construction of students' statistical knowledge, and data analysis starts from the emerging categories of data collected in the project development, considering the objectives set out at each stage. The observed results give evidence that the investigative environment is conducive to motivate students to participate actively in the construction of the concepts inherent in statistics education.
\end{abstract}

Keywords: Environment mathematical modeling, Education Statistics, High School.

\section{Introdução}

A evolução vertiginosa em muitos setores da sociedade tem promovido enormes transformações tecnológicas, sociais e comportamentais, o que exige dos cidadãos cada vez mais conhecimentos, para acompanhar, participar, questionar e usufruir desse desenvolvimento. Diante disso, precisamos redimensionar nossas ações educativas, para possibilitar aos estudantes a aquisição de habilidades para atuar na sociedade como seres independentes, transformadores, capazes de contribuir para o mundo em que vivem. Tal compreensão está de acordo com as ideias de Freire (1979, p. 33), para quem o desenvolvimento de uma consciência crítica que permita ao homem transformar a realidade se faz cada vez mais urgente.

Por isso buscamos uma educação que prepare o aluno para as mudanças sociais e tecnológicas e para participação ativa nos espaços pessoais e profissionais, sem omitir-se, sem sujeitarse aos desmandos dos detentores do conhecimento, das tecnologias, do capital e do poder. Essa perspectiva pressupõe uma educação instigadora, que possibilite aos alunos construir habilidades $\mathrm{e}$ competências para atuar profissionalmente e agir de forma condizente com a sociedade em que vivem.

Buscamos, com este trabalho, discutir as observações realizadas em uma pesquisa de mestrado sobre a construção, em um ambiente investigativo, de conceitos estatísticos por alunos de duas turmas de $3^{\circ}$ ano de uma escola estadual na Grande São Paulo; compreender as contribuições desse ambiente para o desenvolvimento do pensamento estatístico de alunos, tomando como objeto de análise suas construções no projeto. É uma pesquisa de natureza qualitativa, cujos dados foram analisados pelas seguintes categorias

\footnotetext{
* Endereço eletrônico: luzinete-mendonca@uol.com.br

** Endereço eletrônico: celilopes@uol.com.br

*** Endereço eletrônico: elizabethzv@uol.com.br
} 
emergentes: Aconteceu a interação? O problema de investigação foi determinado com clareza? As ações empreendidas no processo investigativo possibilitaram a compreensão do tema? Cada categoria foi dividida em subcategorias, as quais atendiam à diversidade de aspectos observados no material produzido e no processo empreendido em cada etapa do projeto.

\section{A Educação Estatística e a Modelagem Matemática no Ensino Médio}

As propostas curriculares de Matemática nas últimas décadas têm evidenciado a importância do ensino da Estatística para auxiliar no desenvolvimento de competências como: a articulação entre as diferentes áreas; a observação de regularidades dos dados; a construção e a análise de representações gráficas; a análise e o uso de modelos matemáticos; e a vivência com uma forma diferenciada de raciocinar em Matemática, pois a Estatística utiliza uma forma própria de raciocínio, diferente do raciocínio matemático - este centrado na lógica e independente de contextos. $\mathrm{O}$ raciocínio estatístico exige o reconhecimento da incerteza presente em alguns fenômenos e tem, no contexto, a base para interpretações e compreensões. Pesquisadores dessa área ponderam que o raciocínio estatístico dá suporte para uma leitura eficiente das informações estatísticas comumente encontradas no dia a dia, competência denominada "literacia estatística" ou "letramento estatístico" considerada essencial para um indivíduo atuar na sociedade atual (BATANERO, 1999; CARVALHO, 2001; GARFIELD; GAL, 1999; LOPES, 1998, 2003a).

Para que isso se concretize, é fundamental um ambiente de aprendizagem em que o aluno participe ativamente, vivencie situações reais e tenha que fazer investigações. Skovsmose (2000) chama de "cenário de investigação" um ambiente dessa natureza, capaz de dar suporte a um trabalho nessa perspectiva. Assim também propõe Lopes (2004), que entende o processo de ensino e aprendizagem da Estatística de forma dinâmica, em que os alunos levantam questionamentos, geram e analisam dados e, a partir dessas ações, tomam decisões.

Nessa concepção, cabe ao docente proporcionar um ambiente em que seja possível definir a questão ou problema; coletar, organizar, representar e interpretar dados; tomar decisão com base nos dados; e retomar esse processo, de acordo com a necessidade (LOPES, 2004). Nessa perspectiva, o aluno é ativo no processo investigativo, que objetiva responder a questões inicialmente propostas, remetendo-nos ao trabalho com projetos, o qual favorece a integração dos conceitos, no aspecto disciplinar e no interdisciplinar, e pode propiciar formação mais geral e integrada, conforme destaca Lopes (2003b, p. 24): “[...] para compreender um conceito é necessário estabelecermos relações significativas com outros conceitos, quanto mais entrelaçada a rede de conceitos, maior a capacidade para estabelecer relações e, portanto, para compreender os fatos próprios dessa área".

As diversas relações que se operam durante os processos de investigação podem contribuir para dar significados aos conceitos, e a introdução destes em situações reais permite ao aluno compreender as necessidades que motivaram a humanidade a desenvolvê-los, o que ampliará sua visão da ciência como um conhecimento construído. Essa visão favorece a desmistificação da ideia de que a Matemática é um conhecimento preexistente na natureza, acessível apenas a alguns poucos privilegiados intelectualmente.

Nesse sentido, são importantes os ambientes de aprendizagem que demandem a participação ativa dos alunos na busca de compreender temas referentes à realidade, como preconizam Batanero e Diaz (2004). Eles sugerem a introdução da análise exploratória de dados no Ensino Médio por meio do trabalho com projetos, o que possibilita contextualizar os conteúdos em situações reais, integrando o ensino da Estatística a um processo mais geral de investigação.

Em lugar de introduzir os conceitos $e$ técnicas descontextualizadas, ou aplicar unicamente problemas abstratos que não se encontram na vida real, trata-se de apresentar as diferentes fases de uma investigação estatística: Planejamento de um problema, decisão sobre os dados a serem recolhidos, a análise dos dados $e$ obtenção de conclusão sobre o problema apresentados. (BATANERO; DIAZ, 2004, p. 2)

Nesta concepção, a Estatística é considerada uma ferramenta para a resolução dos problemas encontrados no decorrer do projeto, e a Matemática é essencial ao processo de interpretação que ocorre em função do contexto do problema. Nessa visão, o 
professor deve contribuir para a construção do conhecimento de seus alunos por meio dos questionamentos, e não pela indicação do caminho ou de respostas. Tal ideia é compartilhada por Barbosa (2007), Batanero e Diaz (2004), Jacobini (1999), Meyer (2007) e Skovsmose (2000).

Portanto, os questionamentos do professor devem direcionar, instigar e motivar os alunos a buscar métodos, conceitos e ações que levem à compreensão dos temas ou dos fenômenos em questão. A intervenção questionadora do professor exige dele visão abrangente e formação sólida dos conceitos da ciência com a qual lida, para ajudar os alunos a desenvolver-se e a construir o próprio conhecimento. Esta é também a recomendação de Freire e Faundez (1998, p. 48): "O que o professor deveria ensinar - porque ele próprio deveria sabê-lo - seria, antes de tudo, ensinar a perguntar. Porque o início do conhecimento, repito, é perguntar. E somente a partir de perguntar é que se deve sair em busca de respostas, e não o contrário".

Essa perspectiva pode auxiliar no desenvolvimento do raciocínio estatístico, o qual requer reconhecimento da necessidade dos dados, a transnumeração (mudança de representação), a percepção da variabilidade, o raciocínio com modelos e a integração da Estatística com o contexto.

Essa proposta considera campo fértil para essa forma de raciocínio os problemas abertos, pois, em uma perspectiva investigativa, os estudantes, ao construírem suas estratégias, passam por etapas, iniciando com modelos de raciocínio simplistas (intuição informal), sem matematização; e, à medida que discutem, apresentam modelos conceituais mais elaborados, "observando tendências, representações gráficas e análise de dados e, ao final, estão não só pensando em modelos, mas também pensando sobre modelos e observando os pontos fortes e fracos de cada modelo" (LESH; AMIT; SCHORR, 1997, p. 82).

O ambiente proposto por esses pesquisadores assemelha-se à ideia de "ambiente de aprendizagem" proposto por Skovsmose (2000), que serviu de base para Barbosa (2001, p.3) definir Modelagem Matemática como "um ambiente de aprendizagem no qual os alunos são convidados a investigar, por meio da Matemática, situações com referência na realidade". Nessa perspectiva, os alunos não têm esquemas definidos a priori e, com suas estratégias e conhecimentos prévios, realizam uma investigação, buscando responder a uma ou mais indagações sobre uma situação real. Nesse processo, usam a matemática como linguagem, fazendo uso de modelos matemáticos e/ou construindo modelos com os dados coletados, buscando evidências e/ou tendências do comportamento de tais dados. Nesse caso, considera-se modelo matemático "qualquer representação matemática da situação em estudo" (BARBOSA, 2007, p.161).

Conforme este autor, quanto menos delimitada for a atividade em um ambiente de modelagem, mais ela colabora para o aluno efetivamente interferir no currículo, pois o caráter aberto das atividades desenvolvidas nesse ambiente possibilita o surgimento de várias estratégias e resultados, além da necessidade de diversos conceitos e de discussões, relações e reflexões, que dificilmente acontecem em ambientes mais fechados.

Outro aspecto relevante no ambiente proposto por Barbosa (2001) é o destaque dado à formulação do problema pelos alunos, capacidade que o autor considera um ponto forte na formação destes, pois exige o desenvolvimento de várias habilidades, como: interação com o tema, criatividade, desprendimento, além de autonomia para elaborar perguntas que ajudem a compreender o fenômeno em estudo, o que Freire e Faundez (1998) e Meyer (2007) julgam fundamental para a formação de cidadãos críticos e profissionalmente capazes de lidar com as situações complexas do cotidiano.

Jacobini (1999) desenvolveu uma pesquisa sobre o ensino de Estatística na perspectiva da modelagem matemática e destacou que os estudantes devem aprender a formular questões; construir e testar hipóteses; escolher o projeto do estudo; coletar efetivamente os dados; escolher os métodos estatísticos; resumir e interpretar informações; apresentar os resultados do estudo; e entender as limitações da inferência estatística, dentro de um contexto prático. Tal perspectiva está em consonância com a Educação Crítica, pois estimula o aluno à reflexão, ao diálogo, à responsabilidade social e à formação ética, entre outros atributos considerados necessários a sua formação.

Nessa mesma direção, Burak (1992) propõe as seguintes etapas para essa implementação: escolha do tema, fase exploratória, formulação do problema ou especificação do interesse, construção do modelo (equacionamento do problema), validação do modelo, reformulação do modelo, interpretação dos resultados. A coluna da esquerda 
do Quadro 1 apresenta a análise pontual de cada uma dessas etapas, com o objetivo de compará-las com as etapas de uma investigação estatística, segundo a ótica de Lopes (2003a).

Com base no paralelo traçado entre as recomendações para o desenvolvimento da Educação Estatística e as etapas propostas para a concretização da Modelagem Matemática na sala de aula, conforme Burak (1992) (coluna da esquerda do quadro 1), apresentamos, detalhada na coluna da direita do Quadro 1, uma proposta de ambiente de aprendizagem para a implementação da Educação Estatística.

Quadro 1 - Processo de investigação estatística em um ambiente de modelagem matemática

\begin{tabular}{|c|c|}
\hline $\begin{array}{c}\text { PROCESSO DE MODELAGEM } \\
\text { MATEMÁTICA }\end{array}$ & $\begin{array}{c}\text { PROCESSO DE INVESTIGAÇÃO } \\
\text { ESTATÍSTICA EM UM AMBIENTE DE } \\
\text { MODELAGEM MATEMÁTICA } \\
\end{array}$ \\
\hline $\begin{array}{l}1 \text { - Escolha do tema } \\
\text { Início do processo de Modelagem. O tema } \\
\text { pode ser sugerido pelo professor ou escolhido } \\
\text { pelos alunos. }\end{array}$ & $\begin{array}{l}1 \text { - Escolha do tema } \\
\text { Formação dos grupos por tema de interesse ou } \\
\text { escolha de um tema pelos grupos previamente } \\
\text { formados. }\end{array}$ \\
\hline $\begin{array}{l}2 \text { - Pesquisa exploratória } \\
\text { Interação entre os membros dos grupos e } \\
\text { destes com o tema, por meio da coleta de } \\
\text { informações sobre o assunto, buscando um } \\
\text { aprofundamento. }\end{array}$ & $\begin{array}{l}\text { 2- Interação } \\
\text { Interação com o tema ou estudo do fenômeno e } \\
\text { período de interação nos grupos, possibilitando as } \\
\text { negociações dos interesses envolvidos e } \\
\text { discussões sobre o tema. }\end{array}$ \\
\hline $\begin{array}{l}3 \text { - Levantamento dos problemas } \\
\text { Formulação do problema de interesse, na } \\
\text { linguagem natural, de forma correta e clara. }\end{array}$ & $\begin{array}{l}3 \text { - Definição da questão ou problema } \\
\text { - Escolha do(s) aspecto(s) do tema. } \\
\text { - Estabelecimento de hipóteses. } \\
\text { - Elaboração da(s) questão(ões) para a } \\
\text { verificação da(s) hipótese(s). }\end{array}$ \\
\hline $\begin{array}{l}4 \text { - Resolução dos problemas - Construção } \\
\text { de modelos } \\
\text { Tradução do problema em linguagem } \\
\text { matemática. Neste caso, o modelo são as } \\
\text { relações estabelecidas entre as variáveis } \\
\text { escolhidas. }\end{array}$ & $\begin{array}{l}4 \text { - Compreensão do problema } \\
\text { - Trabalho de campo. } \\
\text { - Análise exploratória de dados. } \\
\text { - Uso dos conceitos e dos modelos matemáticos e } \\
\text { estatísticos. } \\
\text { - Construção de modelos representativos dos } \\
\text { resultados encontrados. } \\
\text { - Cálculo de índices e medidas estatísticas com os } \\
\text { quais é possível estabelecer relações e tirar } \\
\text { conclusões. }\end{array}$ \\
\hline $\begin{array}{l}5 \text { - Análise crítica } \\
\text { Validação do modelo } \\
\text { Retomada da situação inicial para checar se o } \\
\text { modelo a representa adequadamente. } \\
\text { Reformulação do modelo } \\
\text { Se constatado que o modelo não representa } \\
\text { adequadamente a situação em estudo, este } \\
\text { deve ser reformulado, e as variáveis } \\
\text { escolhidas têm de ser repensadas. } \\
\text { Interpretação dos resultados } \\
\text { Verificação da resolução do problema, em } \\
\text { termos do modelo. Âs vezes, o modelo, } \\
\text { mesmo estando matematicamente correto, não } \\
\text { resolve o problema. }\end{array}$ & $\begin{array}{l}5 \text { - Deduções, conclusões, inferência e } \\
\text { comunicação de resultados } \\
\text { De posse das relações verificadas no processo } \\
\text { investigativo, estas são analisadas e comparadas } \\
\text { às hipóteses estabelecidas. Estas análises devem } \\
\text { possibilitar tirar conclusões e fazer previsões para } \\
\text { a população, com base nos resultados observados } \\
\text { na amostra consultada. } \\
\text { Os resultados encontrados são analisados } \\
\text { criticamente, observando-se sua validade, } \\
\text { capacidade de generalização e possibilidade de } \\
\text { inferência na população em estudo. } \\
\text { A comunicação tem o intuito de informar aos } \\
\text { outros os resultados encontrados e as atitudes que } \\
\text { esses resultados sugerem. }\end{array}$ \\
\hline
\end{tabular}

Fonte: Mendonça (2011). 


\section{Metodologia}

Para observar a dinâmica do ambiente com foco na construção do conhecimento dos alunos, apresentaremos e discutiremos, individualmente, as etapas do projeto e o desempenho dos grupos, por considerar que assim aproximamos a análise do ambiente real e dos objetivos propostos em cada etapa. Os dados foram coletados no material escrito produzido pelos alunos, nas gravações em áudio e vídeo e no diário de campo, que contém as observações e as impressões da pesquisadora no decorrer do projeto. Sendo assim, o processo de análise centrou-se no material produzido pelos alunos, inclusive seus registros, feitos durante a observação do desenvolvimento das atividades. Esses dados nos possibilitaram verificar a recorrência de alguns aspectos que evidenciaram as categorias emergentes.

\section{Primeira e segunda etapas}

Essas duas etapas serão apresentadas aqui ao mesmo tempo, por terem sido propostas conjuntamente para os alunos.

$\mathrm{Na}$ primeira, os alunos foram convidados a pensar em temas de seu interesse e a escolher um que quisessem compreender; e, na segunda, deveriam fazer uma pesquisa sobre ele. Contudo, inicialmente foram informados de que deveriam formar grupos - de no máximo três e no mínimo dois alunos - , por tema, e fazer uma pesquisa para aprofundar seus conhecimentos sobre o assunto escolhido. A limitação para a constituição de grupos se deu em função de considerarmos que grupos com mais de três alunos poderiam provocar conflitos e ociosidade entre seus integrantes e um número grande de duplas aumentaria muito a quantidade de temas a serem investigados, dificultando o atendimento aos grupos pelo professor.

Ao pesquisarem sobre o tema, os grupos deveriam buscar informações para maior compreensão sobre ele, de forma a enriquecer o conhecimento a seu respeito. Em seguida, faríamos nossas intervenções, para instigar os alunos a refletir, discutir e desenvolver o processo de investigação, tendo a Estatística como ferramenta. Com isso, buscamos promover situação propícia para que eles se inteirassem do tema, condição fundamental para o desenvolvimento de um ambiente de modelagem matemática (BARBOSA, 2001).

\section{Análise do desenvolvimento dos grupos na primeira e na segunda etapas}

A análise das duas etapas foi feita conjuntamente, pois ocorreram simultaneamente. Para isso, estabelecemos a seguinte categoria de análise: “Aconteceu a interação?", que foi subdividida em quatro subcategorias: (1) o envolvimento dos grupos com o tema; (2) o comprometimento e as discussões dos participantes; (3) a busca de dados relevantes para construir subsídios para a compreensão do tema; e (4) a autonomia dos grupos nesse processo, aspectos fundamentais para o desenvolvimento do Projeto de Investigação Estatística, conforme Batanero e Diaz (2004), Jacobini (1999) e Lopes (2003b).

Foram observadas as ações dos grupos na busca de material e os argumentos apresentados no relatório inicial, nas discussões no grupo e com a pesquisadora.

De forma geral, os resultados encontrados revelam que essa primeira fase atingiu os objetivos propostos, pois houve um bom envolvimento da maioria dos grupos com os temas escolhidos, o que, no entanto, precisou ser estimulado em várias ocasiões, confirmando a pertinência da proposta de Oliveira e Campos (2007): em um ambiente de modelagem, é preciso constante renovação do convite, para que os alunos permaneçam motivados a participar do processo. Os resultados também indicam a necessidade de estimular o desenvolvimento das habilidades de cooperação e autonomia, pois alguns estudantes, talvez porque não estivessem acostumados com essa forma de organização da sala de aula, não assumiram o seu papel no grupo; e muitos deles, não tendo conseguido construir argumentos para posicionar-se nas discussões, permaneceram passivos.

\section{Terceira etapa}

Nessa etapa, foi sugerido aos grupos que escolhessem aspectos do tema - pois seria impossível pesquisar os temas de forma completa -, estabelecessem hipóteses sobre eles e, valendo-se de suas crenças e das informações pesquisadas, elaborassem questões que contribuíssem para coletar dados necessários para compreender o assunto e verificar as hipóteses. Tais questões deveriam conter, preferencialmente, variáveis quantitativas (discretas e contínuas) e qualitativas, o que poderia enriquecer o processo de investigação estatística. A sistematização desses e de outros 
conceitos foi sendo feita à medida que isso se mostrou necessário, porém, para que os alunos desenvolvessem sua autonomia, foram estimulados a compreendê-los, consultando o material de apoio a eles oferecido.

Esta etapa foi a mais difícil para os estudantes, o que confirma a previsão de Batanero e Diaz (2004) e de Barbosa (2007) de que ela demanda muita intervenção do professor, para ajudar os alunos na construção de questões que possibilitem a coleta de dados relevantes para a compreensão do tema. Tal dificuldade pode ser justificada pelo fato de esses alunos terem tido poucas oportunidades para elaborar perguntas em sua vida escolar. Além disso, uma grande dificuldade dos alunos na escrita comprometeu essa elaboração.

\section{Análise do desenvolvimento dos grupos na terceira etapa}

A qualidade das discussões em grupo, a autonomia para buscar os conceitos ou as informações, o trabalho cooperativo e a coerência das questões elaboradas caracterizaram esta etapa, para a qual estabelecemos a seguinte categoria de análise: "O problema de investigação foi determinado com clareza?", dividida em cinco subcategorias: (1) discussões e reflexões no grupo; (2) coerência entre os aspectos, as hipóteses, as perguntas e suas alternativas; (3) diversidade de variáveis apresentadas; (4) autonomia; e (5) cooperação.

Nessa etapa, os grupos do $3^{\circ}$. A demonstraram boa apreensão da proposta; no entanto consideramos um aspecto negativo para o desenvolvimento do projeto: a morosidade na realização da atividade comprometeu a distribuição do tempo para as etapas seguintes. Atribuímos isso à pouca familiaridade dos alunos com esse tipo de situação, em que precisam elaborar questões capazes de fornecer informações sobre um tema. Além disso, um fator externo - as interrupções que $o$ projeto sofreu, em função de mudança no cronograma da escola - enfraqueceu a interação dos grupos com seus temas e entre seus componentes. E exigiu mais intervenção, para o restabelecimento da motivação dos alunos.

Nos grupos do $3^{\circ}$. B, de forma geral, não houve o mesmo desempenho nesta etapa: foi alto o índice de grupos com fraco desempenho. $\mathrm{O}$ excesso de faltas e o pouco compromisso por parte de alguns alunos - aliados à interrupção do projeto, à dificuldade desta etapa para alunos pouco habituados a fazer perguntas e à dificuldade de escrita - podem explicar esse fato. Ainda assim, ressaltamos como ponto positivo a participação dos alunos no projeto: em outras ocasiões, esta turma recusou o convite para desenvolver atividades das várias disciplinas.

\section{Quarta e quinta etapas}

$\mathrm{Na}$ quarta etapa, os grupos fizeram a coleta de dados, com a utilização dos conceitos da Estatística e da Matemática, que foram sistematizados à medida que isso foi necessário, de forma geral ou individualmente, nos grupos, quando solicitado. E, na quinta etapa, analisaram os dados e, a partir deles, tiraram conclusões e fizeram inferências, considerando a população pesquisada.

De posse das relações estabelecidas, dos modelos construídos e das tendências observadas no processo investigativo, os grupos fizeram análises e comparações com as hipóteses estabelecidas e examinaram criticamente os resultados encontrados, observando sua validade. A capacidade de generalização dos resultados encontrados e de inferência, objetivo de projetos de investigação estatística em um ambiente de modelagem matemática, como o proposto nesta pesquisa, era um aspecto importante a ser considerado pela pesquisadora.

\section{Análise do desenvolvimento dos grupos na quarta e quinta etapas}

Para essa análise, a categoria: "As ações empreendidas no processo investigativo possibilitaram a compreensão do tema?" foi subdividida nas seguintes habilidades, consideradas subcategorias: (1) usar os conceitos e os modelos matemáticos para a compreensão do tema; (2) construir e utilizar modelos adequados às variáveis escolhidas; (3) estabelecer relações entre variáveis e entre os resultados encontrados e o contexto que os gerou; (4) buscar as informações e os conceitos necessários para o desenvolvimento das atividades; (5) trabalhar de forma autônoma; e (6) trabalhar de modo cooperativo.

A análise dessas duas etapas pela pesquisadora demandou um detalhamento profundo do desenvolvimento e das construções de cada grupo, nas duas etapas. Diante da impossibilidade de apresentá-lo neste trabalho, optamos por expor as construções de um dos grupos, tomando uma de 
suas questões para discussão.

$\mathrm{Na}$ quarta etapa do projeto, o grupo "Consumismo", composto por três alunos, teve, inicialmente, dificuldades na elaboração das questões, em função das faltas de colegas. Além disso, solicitava constantemente nossa orientação para ajudá-lo a pensar que questões elaborar. Nossa intervenção se deu de forma questionadora, levando os alunos a refletir: "O que vocês querem saber sobre o tema?", "Quais os aspectos escolhidos?", "Que hipótese vocês têm sobre isso?", "Como comprová-las?".

Os questionamentos iam direcionando os alunos na elaboração de perguntas que fornecessem dados para sua análise, mas, a cada questão elaborada, eles solicitavam nossa aprovação. Ainda assim, o grupo apresentou uma significativa diversidade de variáveis e formulou perguntas que, em sua maioria, estavam coerentes com as hipóteses estabelecidas. As dificuldades e a insegurança na elaboração de questões para obtenção de dados em todos os grupos - obviamente, em uns mais que em outros - confirmam as discussões apresentadas na literatura e mostram o quanto é necessário promover situações dessa natureza para o desenvolvimento dessa habilidade.

No início da quarta etapa, chamamos a atenção dos grupos para a população e a amostra a ser consultada. Também discutimos os limites da pesquisa, os procedimentos e os instrumentos de coleta de dados. Nessa ocasião, negociamos que seria feita uma pesquisa de opinião e seria elaborado um questionário com questões fechadas, em função das dificuldades para a categorização das respostas abertas no curto tempo do projeto. Naquele momento esses conceitos foram sistematizados.

Os alunos do grupo "Consumismo" inicialmente tiveram dificuldades para fazer a trabalho de campo, por complicações na reprodução dos formulários, o que retardou as entrevistas. Porém, quando as fizeram, trabalharam cooperativamente, dividindo as tarefas (cada um dos 3 alunos fez 15 entrevistas) e organizando o desenvolvimento das atividades.
Embora não tenha demonstrado iniciativa para buscar informações e conceitos, preferindo pedir orientação para organizar os dados coletados, o grupo seguiu as orientações e transferiu as sistematizações - apresentadas coletivamente - para sua pesquisa, ainda que, por vezes, pedisse orientação particular. Para organizar os dados obtidos, a equipe elaborou inicialmente uma tabela de dados brutos para responder aos nossos questionamentos: "Suas hipóteses foram confirmadas?", "Como vocês classificariam as pessoas de suas amostras em relação à idade? Jovens? Idosos?", "Qual a idade que aparece mais vezes?", "Qual a média de idade das pessoas de suas amostras?", "Será que existe alguma relação entre o consumismo e a alta carga de trabalho dos entrevistados?". Tais questões tinham o objetivo de orientar a organização dos dados de forma geral e atender à necessidade de elaboração do resumo de cada uma das questões.

Para responder a esses e outros questionamentos, o grupo se baseou nos modelos encontrados na pesquisa bibliográfica e em uma pesquisa do instituto Akatu (2009) que utilizava tabelas e gráficos para resumir e expor os resultados. Desse modo, o grupo elaborou, sem dificuldade, as tabelas de frequências e os gráficos para todas as questões, revelando domínio dos procedimentos de cálculos e do uso da ferramenta tecnológica. Ademais, preparou representações gráficas adequadas para a maioria das variáveis escolhidas.

O comportamento inicial do grupo, de dependência e insegurança, era o mesmo de todos os outros, nas duas turmas. Contudo, no decorrer do projeto, houve uma emancipação, cada um no seu tempo, na busca de resolução dos problemas. Vale ressaltar o envolvimento e a motivação como fatores fundamentais para esse desenvolvimento. Para melhor expor a trajetória do grupo, apresentaremos a seguir uma de suas questões, os modelos construídos e as conclusões. A partir deles, faremos algumas considerações:

3- O que leva as pessoas a consumirem tanto?
A) ( ) Vaidade
B) ( ) Propagandas
C) ( ) Problemas emocionais

Tabela 1 - Tabela de frequência da questão 3 - grupo Consumismo. 


\begin{tabular}{|c|c|c|c|c|}
\hline Letra & $\begin{array}{c}\text { Frequência } \\
\text { Absoluta }\end{array}$ & $\begin{array}{c}\text { Frequência } \\
\text { Relativa }\end{array}$ & $\begin{array}{c}\text { Frequência } \\
\text { Percentual }\end{array}$ & $\begin{array}{c}\text { F. P. } \\
\text { Acumulada }\end{array}$ \\
\hline A & 12 & $12 / 45=0,2666$ & 26,66 & 24,44 \\
\hline B & 17 & $17 / 45=0,3777$ & 37,77 & 64,43 \\
\hline C & 16 & $16 / 45=0,3555$ & 35,55 & 99,98 \\
\hline Total & 45 & 1 & 99,98 & 99,98 \\
\hline
\end{tabular}

Fonte: Grupo Consumismo, 2008.

\section{Figura 1- Gráfico da questão 3}

\section{Questăo 3}

\section{Por que as pessoas consomem tanto}

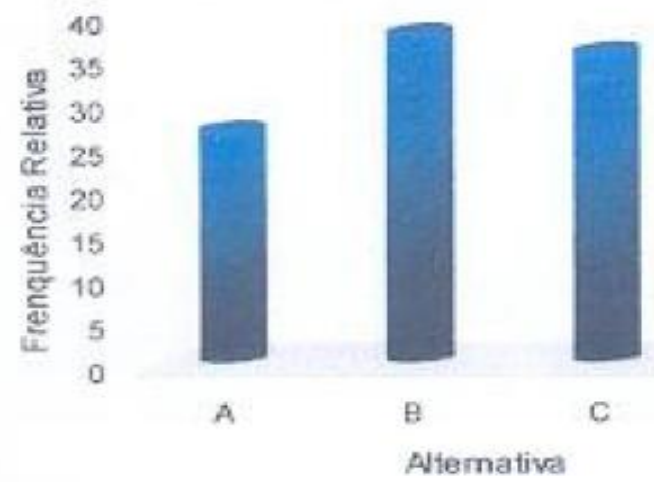

Fonte: Grupo Consumismo, 2008.

Análise dos resultados da questão 3.

Segundo nossas pesquisas, $37,77 \%$ das pessoas afirmam que as propagandas influenciam as pessoas a consumirem tanto, sendo esse resultado da grande maioria, contrariando nossa opinião, pois, acreditamos que o que leva as pessoas a consumirem, de certa forma, são problemas emocionais e psicológicos, ou motivações socioeconômicas, como uma espécie de compensação pela frieza do convívio social, pela carência financeira, por uma autoestima deteriorada e por tantas outras razões. $O$ resultado dessa atitude impulsiva é geralmente o endividamento crescente, então o indivíduo assume uma sobrecarga de trabalho, tentativa de eliminar as dividas [...]. (GRUPO CONSUMISMO, 2008)

A questão elaborada revela coerência com os objetivos do grupo de buscar informações para o aprofundamento do tema, apesar de apresentar poucas alternativas de respostas e de estas serem tendenciosas, já que só consideram os aspectos negativos, o que, provavelmente, reflete a posição do grupo. $\mathrm{O}$ fato de as alternativas apresentarem poucas opções de respostas restringe a expressão da opinião pelos entrevistados, o que já é uma limitação das questões objetivas. Esse problema poderia ser minimizado com um número maior de alternativas, já que uma questão objetiva dificilmente consegue levar em consideração a gama de subjetividades do ser humano. Essa situação possibilitou a discussão sobre a não neutralidade das pesquisas; sobre a importância de saber analisar os resultados que nos são apresentados; e sobre os interesses daqueles que produzem essas pesquisas.

O comportamento do grupo mostrou a relevância de promover ambientes ou situações em que os alunos precisem fazer perguntas para buscar informações sobre um tema, como discutimos inicialmente. A análise dessa questão revela que essa habilidade não parece estar bem desenvolvida, já que a pergunta foi elaborada de forma extremamente tendenciosa. Contudo, a vivência e a reflexão sobre a questão, os resultados e as 
conclusões podem levar ao amadurecimento do espírito investigativo dos alunos, dando-lhes condições para construir a habilidade de elaborar questões ricas e coerentes com os objetivos da pesquisa. Consideramos possível afirmar que, em uma próxima atividade em que precisem elaborar questões, os alunos desse grupo, no mínimo, refletirão mais sobre as possíveis alternativas. Também ousamos pensar que isso se estenda a todos que vivenciaram o projeto.

Os modelos construídos se mostraram capazes de resumir e revelar o comportamento dos dados coletados na pesquisa e possibilitaram ao grupo a análise desse comportamento, usando os índices calculados no primeiro modelo construído (tabela 1). Contudo, a leitura feita pelo grupo foi superficial, já que, em sua análise, o grupo destacou o índice de 37,77\% (alternativa B), chamando-o de "grande maioria", provavelmente por este ser o maior índice, desconsiderando outros dois índices próximos dele e os demais.

O grupo tentou estabelecer relações entre os resultados dessa questão e os de outras por meio de frases como: "[...] então o indivíduo assume uma sobrecarga de trabalho, tentativa de eliminar as dívidas [...]". Nesse caso, o grupo refletiu sobre o resultado encontrado e a hipótese estabelecida para a pergunta, o que indica que o grupo caminha para o desenvolvimento do pensamento estatístico, já que assume uma postura investigativa, considerando o processo como um todo. Ou seja, retoma a hipótese inicial, comparando-a com os resultados encontrados. Esse comportamento ocorreu no decorrer do trabalho desse grupo e em vários grupos das duas turmas. No que se refere aos procedimentos de cálculo, o grupo aqui analisado mostra um bom desempenho, demonstra agilidade e clareza de procedimentos e domínio dos conceitos, fazendo, inclusive, questão de mostrar passo a passo sua construção, como pode ser observado nas tabelas.

De forma geral, há diferenças significativas entre os grupos da mesma turma e entre as duas turmas. Consideramos o desenvolvimento do $3^{\circ}$. A mais proveitoso que o do $3^{\circ} \mathrm{B}$, em função de seu maior envolvimento no projeto. Ainda assim, foi importante a participação dos alunos do $3^{\circ} \mathrm{B}$ na atividade, principalmente se ponderarmos que eles haviam tido poucas oportunidades de envolvimento efetivo no processo de ensino e aprendizagem durante sua escolaridade. Porém, mesmo assim, demonstraram, em vários momentos deste trabalho, interesse e atitudes criativas e reflexivas, principalmente nas discussões sobre o papel da Matemática e, particularmente, da Estatística, na sociedade e na mídia.

Contudo, o projeto poderia ter explorado mais as discussões, envolvendo a possível ineficiência das perguntas elaboradas pelos grupos; os modelos usados e construídos por eles; suas análises equivocadas; e as questões referentes a atitudes e procedimentos no decorrer do projeto. No entanto, o pouco tempo destinado ao seu desenvolvimento e as interrupções impossibilitaram essa exploração e também comprometeram a apresentação dos grupos, parte importante para a socialização das estratégias e dos resultados. Tais questões, que envolvem fatores "externos" ao trabalho docente, precisam ser mais exploradas no ambiente de modelagem, o que passa também por discussões sobre a gestão escolar, aspectos que merecem ser o foco de futuras investigações.

\section{Considerações}

Ao propor um projeto em que os alunos participariam ativamente da construção do próprio conhecimento, tínhamos consciência de que essa não seria uma tarefa simples, considerando a complexidade e a tradição do ambiente escolar. Mesmo com a aceitação do convite inicial, consideramos importante manter a motivação dos alunos durante todo o projeto, razão pela qual o convite foi reiterado em vários momentos, para assegurar a continuidade do trabalho.

Retomando o referencial teórico construído, compreendemos que as etapas propostas no processo de modelagem matemática na Educação e aquelas consideradas importantes no processo de ensino e aprendizagem da Estatística são convergentes, por isso consideramos pertinente indicar que o Processo de Investigação Estatística em um ambiente de modelagem matemática é a própria Modelagem, já que ele, necessariamente, passa pelas etapas de um processo de Modelagem, o que ficou evidente no paralelo traçado entre o processo de modelagem proposto por Burak (1992) e o processo de investigação estatística proposto por Lopes (2003a), e nos forneceu subsídios para a implementação do trabalho de campo, cujos dados possibilitaram observar o desenvolvimento dos alunos no que se refere à construção dos conceitos estatísticos. Nesse sentido, consideramos que o ambiente de modelagem proporciona o envolvimento e a discussão, o que serve de estímulo para a construção dos conceitos, dos procedimentos 
e das atitudes referentes a esta ciência e para o desenvolvimento do pensamento estatístico dos alunos.

A falta de ação construtiva demonstrada por alguns alunos, em determinados momentos, ao que nos parece, tem raízes profundas, fixadas ao longo da sua vida escolar: sempre assistiram, passivamente e de forma completamente descomprometida, a aulas expositivas, com o objetivo de obter nota para "passar de ano", cultura reforçada pela escola, de forma geral.

Assim, podemos concluir que um ambiente de modelagem matemática pode contribuir para despertar o interesse dos alunos em participar de forma ativa da construção do próprio conhecimento estatístico e para propiciar a percepção da utilidade dos conhecimentos escolares para a resolução de problemas, atribuindo significado aos conceitos. Consideramos, ainda, que esse ambiente pode promover a formação de pessoas com capacidade de atuar na sociedade de forma ativa e reflexiva. Contudo, julgamos que a escola ainda precisa aprender a valorizar e apoiar o professor que se dispõe a desenvolver ambientes dessa natureza, pois a organização da escola pode interferir positivamente ou negativamente nessas iniciativas.

\section{Referências}

BARBOSA, J. C. Modelagem na educação matemática: contribuições para o debate teórico. In: REUNIÃO ANUAL DA ANPED, 24., 2001, Caxambu. Anais... Caxambu: ANPED, 2001.

Modelagem matemática: o que é? Por quê? Como? Veritati, Salvador, n. 4, p.73-80, 2004.

A prática dos alunos no ambiente de modelagem matemática: o esboço de um framework. In: BARBOSA, J. C. CALDEIRA, A.;

ARAÚJO, J. (Org.). Modelagem matemática na educação matemática brasileira: pesquisas e práticas educacionais. Recife: SBEM, 2007. p. 16174.

BATANERO, C. Didática de la probabilidade y estatística. Granada: Universidade da Espanha, Departamento de Didáctica de la Matemática, 1999. Mimeografado.
BATANERO, C.; DIAZ, C. El papel de los proyectos en la enseñanza y aprendizaje dela estadística. In: ROYO, J. P. (Ed.). Aspectos didácticos de las matemáticas. Zaragoza: ICE, 2004. p. 125-63.

BURAK, D. Modelagem matemática: ações e interações no processo de ensino e aprendizagem. 1992. 460 f. Tese (Doutorado) - Universidade Estadual de Campinas, Campinas, 1992.

CARVALHO, C. Interacção entre pares: contributos para a promoção do desenvolvimento lógico e do desempenho estatístico, no $7^{\circ}$ ano de escolaridade. 2001. 533f. Tese (Doutorado) Universidade de Lisboa, Lisboa, 2001.

FREIRE, P. Educação e mudança. 27. ed. São Paulo: Paz e Terra, 1979. 79 p.

; FAUNDEZ, A. Por uma pedagogia da pergunta. 4. ed. Rio de Janeiro: Paz e Terra, 1998. $158 \mathrm{p}$.

GARFIELD, J.; GAL, I. Teaching and assessing statistical reasoning. In: STIFF, L.; CURCIO, F. (Org.). Developing mathematical reasoning in grades K-12. USA: National Council of Teachers of Mathematics, 1999. p. 207-19.

INSTITUTO AKATU. Estilos sustentáveis de vida - resultados de uma pesquisa com jovens brasileiros. São Paulo: Instituto Akatu, 2009. Disponível em: $<$ http://www.akatu.org.br/Content/Akatu/Arquivos/f ile/Publicacoes/EstilosSustentaveisdeVida.pdf)>.

Acesso em: 2 abr. 2012.

JACOBINI, O. R. A modelação matemática aplicada no ensino de Estatística em cursos de graduação. 1999. 131 f. Dissertação (Mestrado em Ensino e Aprendizagem da Matemática e seus Fundamentos Filosófico-Científicos) - Universidade Estadual Paulista, Rio Claro, 1999.

LESH, R.; AMIT, M.; SCHORR, R. Using real-life problems to prompt students to construct conceptual models for statistical reasoning. In: GAL, I.; GARFIELD, J. (Ed.). The assessment challenge in statistics education. Amsterdam: The International Statistical Institute, 1997. p. 65-83.

LOPES, C. E. A probabilidade e a estatística no 
Ensino Fundamental: uma análise curricular. 1998. 133 f. Dissertação (Mestrado em Educação) Faculdade de Educação, Universidade de Campinas, Campinas, 1998.

\section{O conhecimento profissional dos professores e suas relações com estatística e probabilidade na educação infantil. 2003. 290 f. Tese (Doutorado em Educação Matemática) - Faculdade de Educação, Universidade Estadual de Campinas, Campinas, 2003a.}

- O conhecimento matemático adquirido através dos projetos. In: LOPES, C. E. Matemática em projetos: uma possibilidade. Campinas, SP: Graf. FE/UNICAMP, CEMPEM, 2003b. p. 23-27.

Literacia estatística e INAF 2002. In: FONSECA, M. C. (Org.). Letramento no Brasil: habilidades matemáticas. São Paulo: Global, 2004. p. 187-97.

MENDONÇA, L. O. Modelagem matemática: um ambiente de aprendizagem para a implementação da educação Estatística. Bolema: Boletim de Educação Matemática, Rio Claro, v. 24, n. 40, p. 701-724, 2011.

MEYER, J. F. C. A. Entrevista. In: CONFERENNCIA NACIONAL SOBRE MODELAGEM NA EDUCAÇÃO MATEMÁTICA, 5, 2007, Ouro Preto. Anais... Ouro Preto: UFOP/UFMG, nov. 2007.

OLIVEIRA, A. M. P; CAMPOS, I. S. As estratégias do professor a partir do 'convite inicial' nas atividades de modelagem matemática. In: CONFERÊNCIA NACIONAL SOBRE MODELAGEM NA EDUCAÇÃO MATEMÁTICA, 5., 2007, Ouro Preto. Anais... Ouro Preto: UFOP/UFMG, 2007. p. 239-52. 1 CDrom.

SKOVSMOSE, O. Cenários para investigação. Bolema: Boletim de Educação Matemática, Rio Claro, ano 13, n. 14, p. 66-91, 2000.

\section{Sobre as autoras:}

Luzinete de Oliveira Mendonça: Professora da UNISO (Universidade de Sorocaba) em curso de pósgraduação em Psicopedagogia. Doutoranda em Ensino de Ciências e Matemática na Universidade Cruzeiro do Sul. São Paulo.

Celi Espasandin Lopes: Professora Titular do Programa de Pós-Graduação em Ensino de Ciências e Matemática da Universidade Cruzeiro do Sul. São Paulo.

Elizabeth Soares: Professora do Centro Universitário Sant'Anna (UniSant'Anna) em cursos de Graduação de Matemática e Pedagogia. Doutoranda em Ensino de Ciências e Matemática na Universidade Cruzeiro do Sul. São Paulo. 